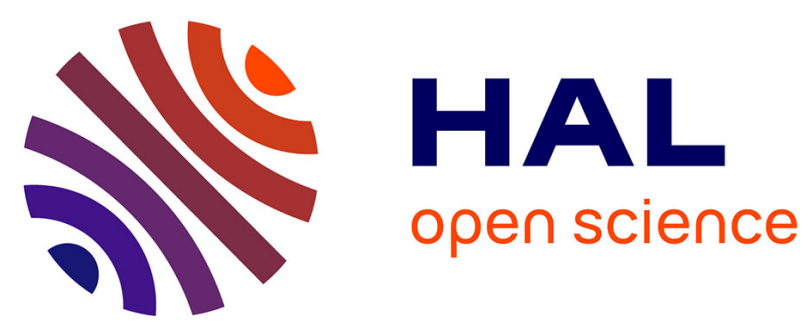

\title{
Sequential binding of calcium ions to the B-repeat domain of SdrD from Staphylococcus aureus
}

Andrei A Roman, François Devred, Vladimir M Lobatchov, Alexander A Makarov, Vincent Peyrot, Aslan A Kubatiev, Philipp O Tsvetkov

\section{- To cite this version:}

Andrei A Roman, François Devred, Vladimir M Lobatchov, Alexander A Makarov, Vincent Peyrot, et al. Sequential binding of calcium ions to the B-repeat domain of SdrD from Staphylococcus aureus. Canadian Journal of Microbiology, 2016, 62 (2), pp.123-129. 10.1139/cjm-2015-0580 . hal-01478554

\section{HAL Id: hal-01478554 \\ https://hal-amu.archives-ouvertes.fr/hal-01478554}

Submitted on 28 Feb 2017

HAL is a multi-disciplinary open access archive for the deposit and dissemination of scientific research documents, whether they are published or not. The documents may come from teaching and research institutions in France or abroad, or from public or private research centers.
L'archive ouverte pluridisciplinaire HAL, est destinée au dépôt et à la diffusion de documents scientifiques de niveau recherche, publiés ou non, émanant des établissements d'enseignement et de recherche français ou étrangers, des laboratoires publics ou privés. 


\title{
Sequential binding of calcium ions to the B-repeat domain of SdrD from Staphylococcus aureus
}

\author{
Andrei Yu. Roman, François Devred, Vladimir M. Lobatchov, Alexander A. Makarov, \\ Vincent Peyrot, Aslan A. Kubatiev, and Philipp O. Tsvetkov
}

\begin{abstract}
Biofilms of live bacteria forming on medical devices and implants contribute significantly to bacterial blood dissemination and to the spread of nosocomial infections. Cell surface SdrD protein plays a key role in the attachment of Staphylococcus aureus to the extracellular matrix (ECM) and in the formation of biofilm. SdrD binds calcium ions using its B1-B5 region bearing EF-hand Ca-binding sites, leading to conformational changes in the structure of SdrD. This alters the distance between the bacterial surface and the ECM-interacting domain of SdrD in a spring-like fashion, participating in bacterial attachment. In this study we investigated calcium binding to EF-hand sites of SdrD using isothermal titration calorimetry and determined the impact of this process on SdrD's thermodynamic stability. This allowed us to propose a model of B1-B5 reorganization upon binding of calcium and to get new insight into the molecular mechanism of SdrD's action.
\end{abstract}

Key words: Staphylococcus aureus, calcium binding, isothermal titration calorimetry, differential scanning calorimetry, protein thermal denaturation, sequential binding model.

Résumé : Les biofilms de bactéries vivantes qui se forment sur les dispositifs et implants médicaux contribuent sensiblement à la dissémination sanguine des bactéries et à la propagation des infections nosocomiales. La protéine de surface cellulaire SdrD joue un rôle crucial dans l'adhérence de Staphylococcus aureus à la matrice extracellulaire et à la formation de biofilm. SdrD se lie aux ions calcium au moyen de sa région B1-B5 renfermant des sites de liaison au Ca de motif «EF-hand », conduisant à des changements conformationnels de la structure de SdrD. Ceci modifie la distance entre la surface bactérienne et le domaine de SdrD interagissant avec la matrice selon un mécanisme rappelant un ressort, rendant ainsi possible l'adhérence de la bactérie. Dans la présente étude, nous avons examiné la liaison du calcium aux sites EF-hand de SdrD au moyen de la calorimétrie de titration isotherme et avons mesuré l'incidence de ce processus sur sa stabilité thermodynamique. Ceci nous a permis de proposer un modèle de réorganisation des domaines B1-B5 déclenchée par la liaison au calcium, et d'élargir notre conception des rouages moléculaires de l'activité de SdrD. [Traduit par la Rédaction]

Mots-clés : Staphylococcus aureus, liaison au calcium, calorimétrie à titrage isotherme, calorimétrie à balayage différentiel, dénaturation thermique de protéines, modèle de liaison séquentiel.

\section{Introduction}

Staphylococcus aureus is a major concern for human health because of its pathogenicity leading to various diseases, such as endocarditis, osteomyelitis, and skin infections (Mongkolrattanothai et al. 2003). The emergence of antibiotic-resistant forms of $S$. aureus and the increasing number of nosocomial infections with this germ has become a worldwide problem in medicine (Diekema et al. 2001; Lowy 2003; Gordon and Lowy 2008). To circumvent this resistance and (or) to find new anti- biotics, it is necessary to understand the mechanisms of action of S. aureus infection and pathogenesis. Among the critical steps of infection in the hospital environment is the attachment of $S$. aureus to the extracellular matrix (ECM) and the formation of biofilm composed of live bacteria. This biofilm can form on indwelling medical devices, such as catheters or implants, leading to blood dissemination and sepsis. Many proteins have been shown to contribute to biofilm formation in staphylococci (Speziale et al. 2014). SdrD is one of the cell surface

Received 3 September 2015. Revision received 28 October 2015. Accepted 3 November 2015.

A.Y. Roman. Aix-Marseille Université, Inserm, CRO2 UMR_S 911, Faculté de Pharmacie, 13385 Marseille, France; Institute of Physiologically Active Compounds, RAS, 142432 Chernogolovka, Russian Federation.

F. Devred and V. Peyrot. Aix-Marseille Université, Inserm, CRO2 UMR_S 911, Faculté de Pharmacie, 13385 Marseille, France.

V.M. Lobatchov and A.A. Makarov. Engelhardt Institute of Molecular Biology, RAS, 119991 Moscow, Russian Federation.

A.A. Kubatiev. Institute of General Pathology and Pathophysiology, RAMS, 125315 Moscow, Russian Federation.

P.O. Tsvetkov. Aix-Marseille Université, Inserm, CRO2 UMR_S 911, Faculté de Pharmacie, 13385 Marseille, France; Institute of General Pathology and Pathophysiology, RAMS, 125315 Moscow, Russian Federation.

Corresponding author: Philipp O. Tsvetkov (e-mail: philipp.tsvetkov@univ-amu.fr). 


\section{Pagination not final (cite DOI) / Pagination provisoire (citer le DOI)}

components implicated in this process. It belongs to a family of at least 5 other serine-aspartate repeat-containing proteins, including fibrinogen binding clumping factors ClfA and ClfB, sharing both organizational and sequence similarity with other family members (Josefsson et al. 1998a). SdrD bears several domains including a ligand binding region A located in its central part and composed of N1, N2, and N3 domains, followed by a region $B$ composed of B1-B5 domains bearing EF-hand $\mathrm{Ca}^{2+}$ binding sites. It was shown that a $\mathrm{Ca}^{2+}$-free $\mathrm{B} 1-\mathrm{B} 5$ region displays a mostly unfolded conformation and that binding of $\mathrm{Ca}^{2+}$ to high-affinity sites in this region leads to formation of a compact conformation with a solventshielded hydrophobic core (Josefsson et al. 1998a). Further study of thermodynamic and kinetic parameters of the interaction of domains $\mathrm{B} 1-\mathrm{B} 5$ with $\mathrm{Ca}^{2+}$ leads to the hypothesis that B-repeats may act as springs that modulate the distance between the interactive A region and the bacterial cell surface (Josefsson et al. 1998b). This was also suggested by a more recent study in which the crystal structure of the interface between the ligandbinding domain and the region B of SdrD (N2-N3-B1) was solved (Wang et al. 2013). To further elucidate the mechanism of SdrD-ligand interaction, we monitored the stability of the B1-B5 region at different temperatures using a combination of differential scanning calorimetry and isothermal titration calorimetry. We demonstrated that even in the absence of calcium ions, certain B1-B5 domains are well structured. We also showed that B1-B5 domains bind calcium ions in a sequential way. This enabled us to propose a new model of sequential structuralization of SdrD upon $\mathrm{Ca}^{2+}$ binding associated with a step-wise shrinking of domains B1 to B5. These findings advance our understanding of S. aureus biofilm formation and could help future studies directed at designing novel antibacterial agents.

\section{Materials and methods}

\section{Protein expression and purification}

The B1-B5 region of SdrD of S. aureus (strain Newman) was expressed and purified as described previously (Josefsson et al. 1998b). Apo state was obtained by adding $1 \mathrm{mmol} / \mathrm{L}$ EDTA followed by dialysis against $50 \mathrm{mmol} / \mathrm{L}$ cacodylate buffer. Protein concentration was determined using a molar extinction coefficient of $68200 \mathrm{~L} /(\mathrm{mol} \cdot \mathrm{cm})$ at $278 \mathrm{~nm}$.

\section{Isothermal titration calorimetry (ITC)}

Binding of $\mathrm{Ca}^{2+}$ ions to the B1-B5 domains of SdrD was analyzed by ITC using a MCS-ITC instrument at $25{ }^{\circ} \mathrm{C}$ in $50 \mathrm{mmol} / \mathrm{L}$ cacodylate buffer, $\mathrm{pH}$ 7.5. The concentration of the B1-B5 region in the calorimetric cell ranged from 0.02 to $0.03 \mathrm{mmol} / \mathrm{L}$, whereas calcium concentration in the syringe varied from 3 to $5 \mathrm{mmol} / \mathrm{L}$. The heat of dilution was measured by injecting the calcium solution into the protein-free buffer solution; the value obtained was subtracted from the heat of reaction to obtain the effective heat of binding. Data were analyzed using the FIT software developed in CRO2 (Aix Marseille University, France) and were fitted with the "sequential binding sites" model (Tsvetkov et al. 2010; Malesinski et al. 2015). Thus, affinity constant $\left(K_{\mathrm{a}}\right)$ and enthalpy changes $(\Delta H)$ for each binding site were obtained, and the Gibbs energy $(\Delta G)$ and the entropy variations $(\Delta S)$ were calculated according to the standard thermodynamic equations.

\section{Differential scanning calorimetry (DSC)}

Heat denaturation measurements were determined with a MicroCal VP-DSC instrument in $0.51 \mathrm{~mL}$ cells at a heating rate of $1 \mathrm{~K} / \mathrm{min}$. Experiments were performed in $50 \mathrm{mmol} / \mathrm{L}$ cacodylate buffer in the presence of $2 \mathrm{mmol} / \mathrm{L}$ EDTA or $2 \mathrm{mmol} / \mathrm{L} \mathrm{CaCl}_{2}$, $\mathrm{pH}$ 7.5. Protein concentration varied from 1.5 to $2.1 \mathrm{mg} / \mathrm{mL}$. Curves were corrected for the instrumental baseline obtained by heating the solvent used for protein solution. The reversibility of denaturation was checked routinely by sample reheating after cooling in the calorimetric cell. The denaturation parameters were determined assuming that the molecular mass of the B1-B5 fragment is 60793 Da and the partial specific volume is $0.72 \mathrm{~cm}^{3} / \mathrm{g}$. To analyze functions of excess heat capacity, MicroCal Origin software was used. The errors in the parameters of individual transitions obtained by deconvolution of complex endotherms did not exceed $\pm 10 \%$ for transition enthalpy and $\pm 0.6{ }^{\circ} \mathrm{C}$ for transition temperature.

\section{Circular dichroism (CD)}

CD spectra were recorded on a Jasco J-715 spectropolarimeter equipped with Peltier-type temperature control system model PTC-423S/L (“Jasco", Japan). The cells had a light path of 0.02 and $1.0 \mathrm{~cm}$, and protein concentration was 0.25 (far-UV CD) and $1.27 \mathrm{mg} / \mathrm{mL}$ (near-UV CD). CD spectra were acquired in $50 \mathrm{mmol} / \mathrm{L}$ cacodylate, $1 \mathrm{mmol} / \mathrm{L}$ $\mathrm{CaCl}_{2}$, pH 7.5 buffer. For continuous melting of the samples, the temperature was increased at a rate of $1 \mathrm{~K} / \mathrm{min}$ (as for DSC), and the transition temperatures were determined from the peaks on the first temperature derivatives of the melting profiles. The results were expressed as molar ellipticity, $[\Theta]\left(\mathrm{deg} \mathrm{cm}^{2} / \mathrm{dmol}\right)$, on the basis of a mean amino acid residue weight (MRW) of 108 (Garnier et al. 1998). The molar ellipticity was determined as $[\Theta]=$ $(\theta \times 100 \mathrm{MRW}) /(c l)$, where $c$ is the protein concentration in milligrams per millilitre, $l$ is the light path length in centimeters, and $\theta$ is the measured ellipticity in degrees.

\section{Results and discussion}

To reveal the presence of tertiary structure in calciumfree B-repeat domain of SdrD (B1-B5), we used differential scanning calorimetry (Tsvetkov et al. 2005). Temperature dependence of the partial molar heat capacity of (B1-B5) in apo state (Fig. 1A, dotted line) shows a large denaturation peak between 35 and $60{ }^{\circ} \mathrm{C}$. The denaturation profile of B1-B5 in the absence of calcium ions is similar to that of another calcium-binding pro- 
Fig. 1. Thermodynamics of $\mathrm{Ca}^{2+}$ binding to B1-B5 domains. (A) Temperature dependence of the partial molar heat capacity of B1-B5 in apo state (dotted line) and calcium-saturated form (solid line). The inset shows the temperature dependence of the excess heat capacity of B1-B5 in apo state and calcium-saturated forms (solid lines), deconvolution peaks (dotted lines), and their sum (dashed lines). (B) Isothermal titration calorimetry (ITC) binding isotherm of calcium to apo B1-B5 titration at $25{ }^{\circ} \mathrm{C}$ in $50 \mathrm{mmol} / \mathrm{L}$ cacodylate buffer, $\mathrm{pH}$ 7.5. The inset shows raw ITC curve of calcium titration into apo B1-B5 solution.
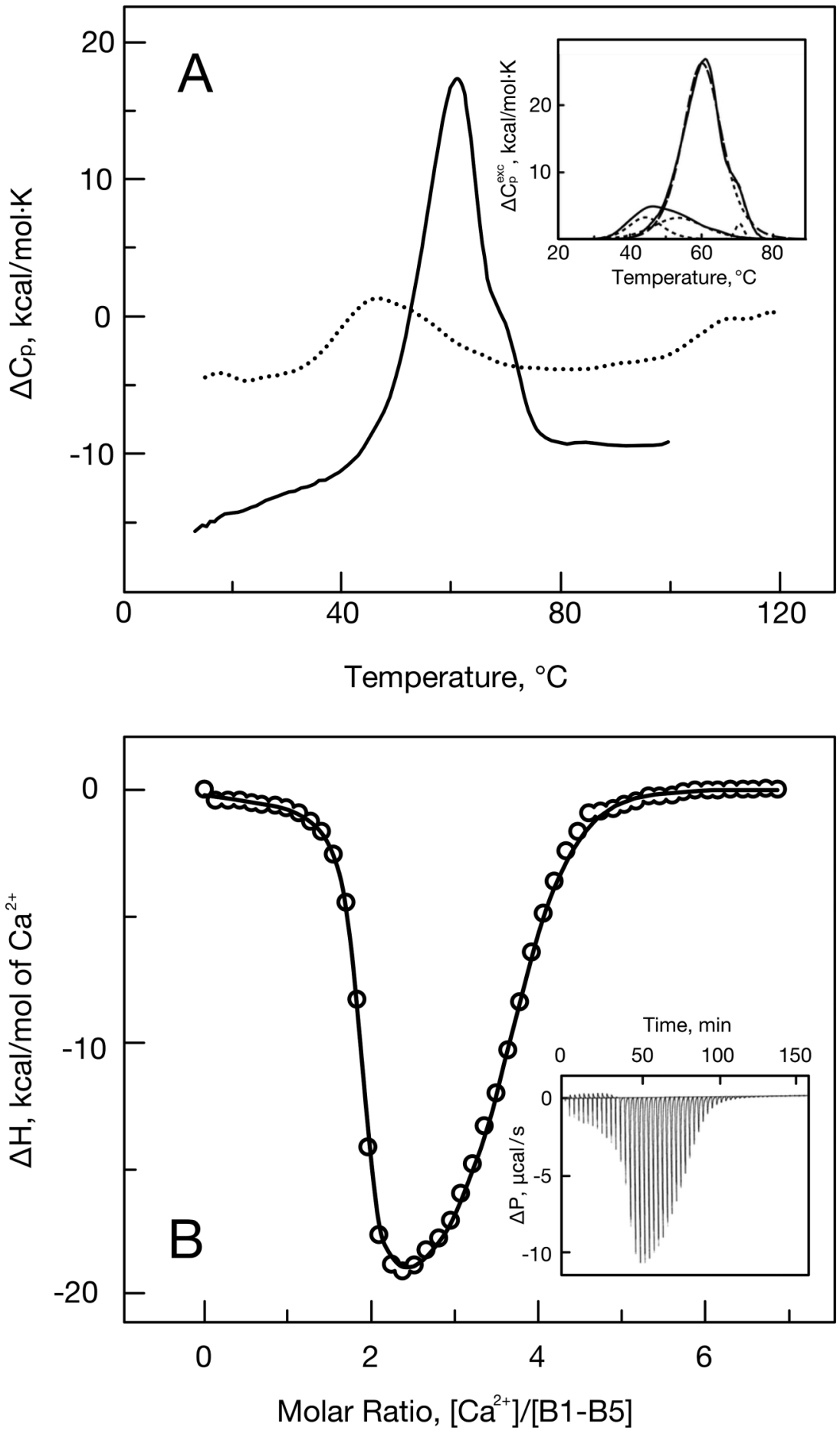

tein, calcium vector protein (CaVP), which possesses 2 canonical and 2 abortive EF-hands (Baladi et al. 2001). Two out of 4 EF-hand domains of CaVP are well structured even in the absence of calcium, while the saturation of CaVP with calcium leads to structuralization of the entire protein (Baladi et al. 2001). Contrary to the denatur- ation of CaVP for which the 2 EF-hand motifs denaturate as a single domain, the denaturation peak of calciumfree B1-B5 can be deconvoluted in 2 "non-two-state" transitions with denaturation temperatures of 44.5 and $53.7^{\circ} \mathrm{C}$ (Fig. 1, Table 1). The ratios of Van't Hoff to calorimetric entropy $(R)$, which indicate the number of do- 
Table 1. Thermodynamic parameters of thermal denaturation of B1-B5 domains of SdrD in $50 \mathrm{mmol} / \mathrm{L}$ cacodylate buffer, pH 7.5.

\begin{tabular}{|c|c|c|c|c|c|c|c|c|c|}
\hline \multirow[b]{2}{*}{ Method } & \multirow[b]{2}{*}{ Form } & \multicolumn{4}{|c|}{ First transition } & \multicolumn{4}{|c|}{ Second transition } \\
\hline & & $\mathrm{T}_{1}\left({ }^{\circ} \mathrm{C}\right)$ & $\begin{array}{l}\Delta H_{1} \\
(\mathrm{kcal} / \mathrm{mol})\end{array}$ & $\begin{array}{l}\Delta H_{\mathrm{v} 1} \\
(\mathrm{kcal} / \mathrm{mol})\end{array}$ & $R$ & $\mathrm{~T}_{2}\left({ }^{\circ} \mathrm{C}\right)$ & $\begin{array}{l}\Delta H_{2} \\
(\mathrm{kcal} / \mathrm{mol})\end{array}$ & $\begin{array}{l}\Delta H_{\mathrm{v} 2} \\
(\mathrm{kcal} / \mathrm{mol})\end{array}$ & $R$ \\
\hline$\overline{\mathrm{DSC}}$ & Apo & 44.5 & 41.7 & 63.5 & 0.65 & 53.7 & 62.7 & 43.8 & 1.4 \\
\hline DSC & $\mathrm{Ca}$ & 60.3 & 380.0 & 70.0 & 5.4 & 70.6 & 7.7 & 221.0 & 0.03 \\
\hline
\end{tabular}

Note: DSC, differential scanning calorimetry. The errors in the parameters of individual transitions obtained by deconvolution of complex endotherms did not exceed $\pm 10 \%$ for transition enthalpy and $\pm 0.6{ }^{\circ} \mathrm{C}$ for transition temperature.

mains melted in a deconvoluted peak, are equal to 0.65 and 1.4 , respectively (Table 1 ). These data clearly demonstrate the presence of more than 1 folding unit (domain) with a tertiary structure in the B1-B5 region even in the absence of calcium ions. The fact that $R$ value is not an integer for both peaks, while their sum is close to 2, allows us to hypothesize that one of the B-repeats can exist in a slow equilibrium between 2 different conformations, which have different stability and consequently melt at different temperatures.

These findings confirm previously published a hypothesis regarding the existence of 2 different kinds of B-motifs (Josefsson et al. 1998a), which would imply that there are at least 2 types of $\mathrm{Ca}^{2+}$ binding sites with different binding parameters. Nevertheless, Josefsson et al. (1998b), with the help of flow dialysis, demonstrated that each B-motif binds calcium ions with the same constant $3.3 \times 10^{5} \mathrm{M}^{-1}$ and positive cooperativity with a Hill coefficient of 1.45 . They also reported the existence of 10 noncooperative sites with a binding constant of about $5.3 \times 10^{3} \mathrm{M}^{-1}$. To resolve this contradiction, we decided to investigate calcium interaction with domains B1-B5 using ITC, which provides full thermodynamic characterization of interaction (Fig. 1B). Binding of calcium ions to the B-repeat region of SdrD was analyzed using a MCS-ITC instrument at $25{ }^{\circ} \mathrm{C}$ in $50 \mathrm{mmol} / \mathrm{L}$ cacodylate buffer at $\mathrm{pH}$ 7.5. Isotherm of calcium binding to the B-repeat was fitted with a "sequential binding sites" model, since no other simpler models provided good experimental data description (Table 2). The thermodynamic data demonstrated that the analyzed fragment of SdrD has calcium-binding sites of high and low affinity association constants (Table 2, Fig. 1B). The best-fitting results were obtained with the 5 sequential binding sites model, which was the most appropriate model considering that the B1-B5 domains of SdrD consist of 5 calciumbinding EF-hand motifs. Table 2 shows that binding of the first 2 calcium ions is mostly entropy-driven $(\Delta S>0)$, which points to burying of the hydrophobic residues upon binding of 2 calcium ions to the B1-B5 region. This burying could occur within a single B-repeat because of the significant conformational changes induced by calcium ions or because of interaction between 2 B-repeats through a hydrophobic interface. Binding of the third and fourth calcium ions is strongly entropyunfavorable, which is compensated by high favorable
Table 2. Thermodynamic parameters of calcium binding to the B1-B5 domains of SdrD in $50 \mathrm{mmol} / \mathrm{L}$ cacodylate buffer, $\mathrm{pH} 7.5$.

\begin{tabular}{llcc}
\hline Site & $K_{a}\left(\mathrm{M}^{-1}\right)$ & $\Delta H(\mathrm{kcal} / \mathrm{mol})$ & $\Delta S(\mathrm{cal} / \mathrm{mol} \cdot \mathrm{K})$ \\
\hline 1 & $(9.6 \pm 4.4) \times 10^{4}$ & $-1.3 \pm 0.5$ & 18.6 \\
2 & $(6.0 \pm 2.6) \times 10^{7}$ & $1.2 \pm 0.6$ & 39.4 \\
3 & $(8.1 \pm 0.7) \times 10^{4}$ & $-19.1 \pm 0.4$ & -41.7 \\
4 & $(5.2 \pm 0.4) \times 10^{4}$ & $-25.4 \pm 0.8$ & -63.5 \\
5 & $(0.9 \pm 0.1) \times 10^{4}$ & $2.6 \pm 0.6$ & 26.6 \\
\hline
\end{tabular}

enthalpy of interaction $(\Delta H<0)$. Such a thermodynamic profile could be explained by entropy-unfavorable structuralization of these 2 unfolded B-repeats in apo state. As with the first sites, binding of the last calcium ion is driven by entropy. This indicates that the domain is already structured, since the interaction is not accompanied by entropy-unfavorable structuralization, as in the case of binding of third and fourth calcium ions. Thus, ITC data demonstrate that 2 repeats in the B1-B5 fragment are structured in apo form. It also shows that the binding of the third calcium ion leads to structuralization of 1 B-repeat, while the fourth calcium ion induces structuralization of the last 2 B-repeats. This is also confirmed by more unfavorable enthalpy in comparison with the third site. Previously, it was shown that each B-repeat is able to bind 2 auxiliary calcium ions with much lower constants (Josefsson et al. 1998b). Nevertheless, the ITC binding isotherm did not reveal any heat exchange after saturation of the 5 sites, when the molar ratio of calcium ions concentration to B1-B5 fragment concentration in solution upon titration exceeds 5. This can be explained by slow kinetics of calcium binding to auxiliary sites (Josefsson et al. 1998b) or by a very low enthalpy of interaction; in this last case, calcium binding to auxiliary sites would be entropy driven with solvent rearrangement associated with burying of hydrophobic areas.

To confirm the global structuralization of the B1-B5 region upon its saturation with calcium ions, we carried out DSC melting of B1-B5 in the presence of $2 \mathrm{mmol} / \mathrm{L}$ $\mathrm{CaCl}_{2}$ (Fig. 1A, solid line). Thermal denaturation of $\mathrm{Ca}^{2+}$ bound B1-B5 demonstrates cooperative transition with a melting temperature centered on $60.9^{\circ} \mathrm{C}$ with a shoulder around $70^{\circ} \mathrm{C}$ (Fig. 1, Table 1). Deconvolution of calorimetric peak on 2 "non-two-state" transitions revealed that 
Fig. 2. Circular dichroism (CD) of $\mathrm{Ca}^{2+}$-bound B1-B5 domains. Far-UV (A) and near-UV (B) CD spectra of domains B1-B5 of SdrD at $20{ }^{\circ} \mathrm{C}$ (solid line) and $90{ }^{\circ} \mathrm{C}$ (dotted line) in $50 \mathrm{mmol} / \mathrm{L}$ cacodylate buffer, $1 \mathrm{mmol} / \mathrm{L} \mathrm{CaCl}_{2}$, $\mathrm{pH}$ 7.5. (C) Normalized CD melting curves of domains B1-B5 of SdrD at $289 \mathrm{~nm}$ (dotted line) and $222 \mathrm{~nm}$ (solid line).

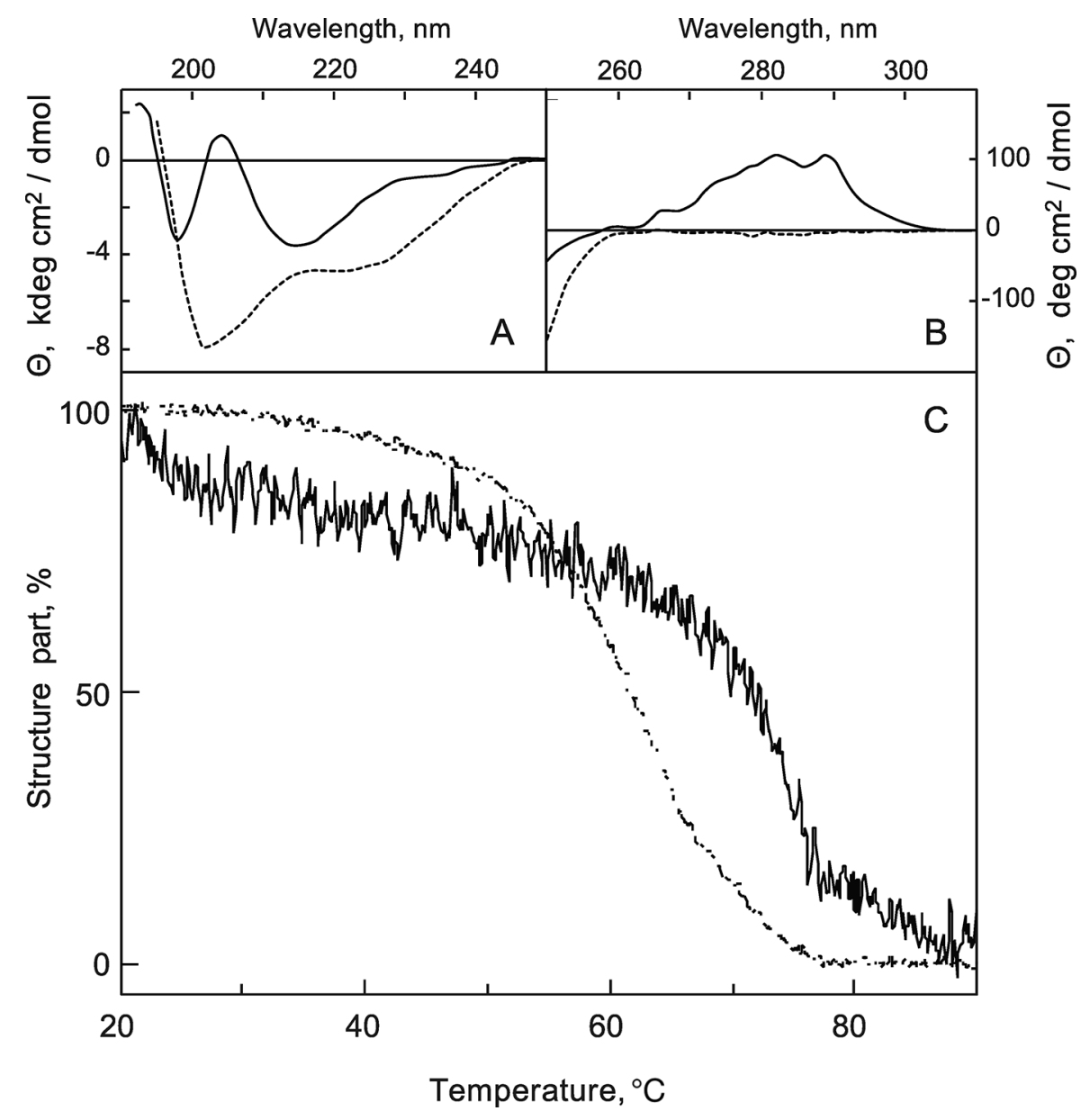

the main peak at $60.3{ }^{\circ} \mathrm{C}$ corresponds to independent denaturation of 5 equal domains, since the ratio of calorimetric enthalpy to Van't Hoff enthalpy is close to 5 (Table 2) and close to the temperature of denaturation of tertiary structure $\left(62.2^{\circ} \mathrm{C}\right)$ followed by near-UV CD melting (Fig. 2). The second deconvolution peak at $70.6{ }^{\circ} \mathrm{C}$ is most probably due to denaturation of elements of secondary structure, since it has very low enthalpy of denaturation and a $R$ factor of $<0.1$. In addition, this value is close to the temperature of denaturation of the secondary structure $\left(74.1^{\circ} \mathrm{C}\right)$ followed by far-UV CD (Fig. 2).

On the basis of our data and previous reports (Josefsson et al. 1998a, 1998b; Wang et al. 2013), we propose a model of B1-B5 region reorganization upon calcium binding, which is summarized in Fig. 3. In the absence of $\mathrm{Ca}^{2+}$, the B1-B5 region of SdrD is globally unfolded but with 2 well-structured domains (Fig. 3A). The functional role of these folded domains could consist of buffering the calcium signal, which would allow SdrD not to shrink before calcium concentration achieves a certain threshold value (Figs. 3B, 3C). As soon as calcium concentration reaches a threshold level, the B1-B5 fragment binds the next calcium ion and shrinks for the first time (Fig. 3D). B1-B5 fragment shrinking is more important at the second threshold, since the next calcium ion binding leads to structuralization of 2 EF-hand domains (Fig. 3E). Further increases in calcium concentration do not impact dramatically on the distance between $\mathrm{N}$ - and C-terminus of SdrD, still it could be modulated by a fifth calcium ion, which can induce interdomain interaction (Fig. 3F).

Even though the exact mechanism of SdrD action is still not completely elucidated, we believe that the sequential $\mathrm{Ca}^{2+}$ mechanism described here has important biological significance in $S$. aureus infections. Indeed, metal chelators have long been part of the molecular arsenal to fight microbes. In particular, since $\mathrm{Ca}^{2+}$ has been shown to modulate the architecture and topography of S. aureus biofilms (Shukla and Rao 2013), a great hope has been to use $\mathrm{Ca}^{2+}$ chelators to prevent $S$. aureus infection by perturbing the early step of its infection (i.e., attachment and biofilm formation) (Banin et al. 2006). Recently, 2 simultaneous studies have shown that $S$. aureus clumping factor B was implicated in biofilm formation in the absence of calcium (Abraham and Jefferson 2012) and that calcium chelating agents could have an opposite effect on biofilm formation, depending 


\section{Pagination not final (cite DOI) / Pagination provisoire (citer le DOI)}

Fig. 3. Model of SdrD functioning as a molecular spring, which shrinks upon calcium binding. (A) In apo state, 3 of 5 B-repeats are unfolded, which allow the N2 and N3 domains to stay as far as possible from the Staphylococcus aureus wall; (B, C) binding of the first 2 calcium ions leads to local conformational changes in corresponding B-repeats but does not impact overall structure; (D) one of the unfolded B-repeats structured upon next calcium ion binding; (E) binding of fourth calcium ion leads to structuring of 2 B-repeats; and (F) binding of last calcium ion does not impact overall structure.

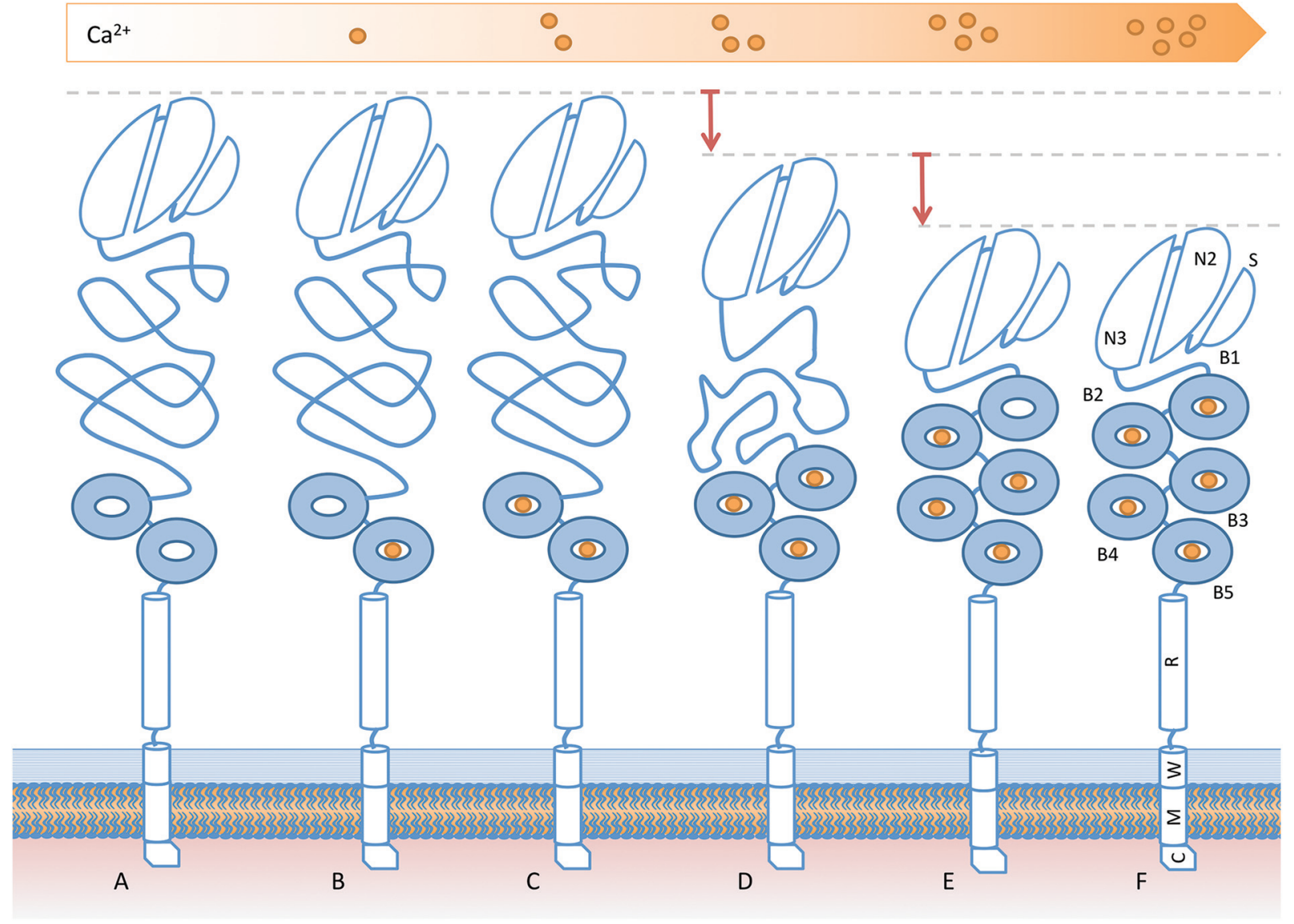

on the strain background (Abraham et al. 2012). We believe that this paradoxal effect of chelator dependence on the strain could be related to the presence of SdrD or another Ca-dependent receptor with a different number of B-domains (Josefsson et al. 1998a). Studying the distribution and relative expression of these different receptors will continue to improve the understanding of molecular aspects of adhesion and biofilm formation, a necessary step to develop strategies against $S$. aureus spreading.

\section{Acknowledgements}

The authors thank Timothy J. Foster for providing purified B1-B5 domains of SdrD and Sveltana Gorokhova for helpful discussion. This work was partly supported by Marie Curie Actions FP7-PEOPLE-2013-IIF\#627524. Microcalorimetry experiments were performed in Timone Microcalorimetry Platform, Marseille, France.

\section{References}

Abraham, N.M., and Jefferson, K.K. 2012. Staphylococcus aureus clumping factor B mediates biofilm formation in the absence of calcium. Microbiology, 158(Pt. 6): 1504-1512. doi:10.1099/ mic.0.057018-0. PMID:22442307.
Abraham, N.M., Lamlertthon, S., Fowler, V.G., and Jefferson, K.K. 2012. Chelating agents exert distinct effects on biofilm formation in Staphylococcus aureus depending on strain background: role for clumping factor B. J. Med. Microbiol. 61(Pt. 8): 1062-1070. doi:10.1099/jmm.0.040758-0. PMID: 22516131.

Baladi, S., Tsvetkov, P.O., Petrova, T.V., Takagi, T., Sakamoto, H., Lobachov, V.M., et al. 2001. Folding units in calcium vector protein of amphioxus: structural and functional properties of its amino- and carboxy-terminal halves. Protein Sci, 10(4): 771-778. doi:10.1110/ps.40601. PMID:11274468.

Banin, E., Brady, K.M., and Greenberg, E.P. 2006. Chelatorinduced dispersal and killing of Pseudomonas aeruginosa cells in a biofilm. Appl. Environ. Microbiol. 72(3): 2064-2069. doi: 10.1128/AEM.72.3.2064-2069.2006. PMID:16517655.

Diekema, D.J., Pfaller, M.A., Schmitz, F.J., Smayevsky, J., Bell, J., Jones, R.N., et al. 2001. Survey of infections due to Staphylococcus species: frequency of occurrence and antimicrobial susceptibility of isolates collected in the United States, Canada, Latin America, Europe, and the Western Pacific region for the SENTRY Antimicrobial Surveillance Program, 1997-1999. Clin. Infect. Dis. 32(Suppl. 2): S114-S132. doi:10.1086/320184. PMID: 11320452.

Garnier, C., Protasevich, I., Gilli, R., Tsvetkov, P., Lobachov, V., Peyrot, V., et al. The two-state process of the heat shock protein 90 thermal denaturation: effect of calcium and magne- 
sium. Biochem. Biophys. Res. Commun. 249(1): 197-201. doi: 10.1006/bbrc.1998.9108. PMID:9705856.

Gordon, R.J., and Lowy, F.D. 2008. Pathogenesis of methicillinresistant Staphylococcus aureus infection. Clin. Infect. Dis. 46(Suppl. 5): S350-S359. doi:10.1086/533591. PMID:18462090.

Josefsson, E., McCrea, K.W., Ni Eidhin, D., O’Connell, D., Cox, J., Hook, M., and Foster, T.J. 1998a. Three new members of the serine-aspartate repeat protein multigene family of Staphylococcus aureus. Microbiology, 144(12): 3387-3395. doi:10.1099/00221287-144-12-3387. PMID:9884231.

Josefsson, E., O'Connell, D., Foster, T.J., Durussel, I., and Cox, J.A. 1998b. The binding of calcium to the B-repeat segment of SdrD, a cell surface protein of Staphylococcus aureus. J. Biol. Chem. 273(47): 31145-31152. doi:10.1074/jbc.273.47. 31145. PMID:9813018.

Lowy, F.D. 2003. Antimicrobial resistance: the example of Staphylococcus aureus. J. Clin. Invest. 111(9): 1265-1273. doi:10. 1172/JCI18535. PMID:12727914.

Malesinski, S., Tsvetkov, P.O., Kruczynski, A., Peyrot, V., and Devred, F. 2015. Stathmin potentiates vinflunine and inhibits paclitaxel activity. PLoS One, 10(6): e0128704. doi:10.1371/ journal.pone.0128704. PMID:26030092.

Mongkolrattanothai, K., Boyle, S., Kahana, M.D., and Daum, R.S. 2003. Severe Staphylococcus aureus infections caused by clon- ally related community-acquired methicillin-susceptible and methicillin-resistant isolates. Clin. Infect. Dis. 37(8): 10501058. doi:10.1086/378277. PMID:14523769.

Shukla, S.K., and Rao, T.S. 2013. Effect of calcium on Staphylococcus aureus biofilm architecture: a confocal laser scanning microscopic study. Colloids Surf. B Biointerfaces, 103: 448-454. doi:10.1016/j.colsurfb.2012.11.003. PMID:23261565.

Speziale, P., Pietrocola, G., Foster, T.J., and Geoghegan, J.A. 2014. Protein-based biofilm matrices in staphylococci. Front. Cell. Infect. Microbiol. 4: 171. doi:10.3389/fcimb.2014.00171. PMID: 25540773.

Tsvetkov, P.O., Ezraty, B., Mitchell, J.K., Devred, F., Peyrot, V., Derrick, P.J., et al. 2005. Calorimetry and mass spectrometry study of oxidized calmodulin interaction with target and differential repair by methionine sulfoxide reductases. Biochimie, 87(5): 473-480. doi:10.1016/j.biochi.2004.11.020. PMID:15820754.

Tsvetkov, P.O., Devred, F., and Makarov, A.A. 2010. Thermodynamics of zinc binding to human S100A2. Mol. Biol. 44(5): 832-835. doi:10.1134/S0026893310050213. PMID:21090249.

Wang, X., Ge, J., Liu, B., Hu, Y., and Yang, M. 2013. Structures of SdrD from Staphylococcus aureus reveal the molecular mechanism of how the cell surface receptors recognize their ligands. Protein Cell, 4(4): 277-285. doi:10.1007/s13238-013-3009-x. PMID: 23549613. 